\title{
CRÍTICA ERRANTE, LITERATURA CLANDESTINA: entreVista CoM Graciela SPERANZA
}

\author{
Tiago Guilherme Pinheiro
}

Graciela Speranza é umas das ensaístas mais interessantes da Argentina contemporânea. Seu trabalho combinado entre literatura e artes plásticas movimenta-se em torno de uma indagação contínua sobre os limites das práticas e teorias estéticas através dos estudos da imagem, essa quase existência fantasmal que tudo atravessa, multiplicando formas.

Desde seus primeiros trabalhos, o percurso de Speranza se desenvolve como uma investigação dos diversos modos de encarnação das imagens. Começa assim produzindo séries de entrevistas para periódicos como Página/12 e Clarín, as quais depois seriam recolhidas em dois importantes livros: Primera persona (1995) e Partes de guerra (1997). O primeiro reúne as transcrições de diálogos com os grandes escritores argentinos do período - de David Viñas a César Aira, passando por Fogwill, Héctor Tizon, Sylvia Molloy, Juan José Saer e outros -, acompanhados por fotografias de Alejandra Lopes e prefácio de Beatriz Sarlo. Já o segundo, escrito com Fernando Cittadini, recolhe depoimentos e testemunhos de 20 sobreviventes da Guerra das Malvinas, é bem recebido pela crítica e ganha uma resenha entusiasmada de Ricardo Piglia.

Ambos os volumes são organizados como uma coleção de retratos, esse subgênero derivado da pintura - hoje um tanto esquecido, mas largamente praticado pela crítica literária dos séculos XVI e seguintes - no qual, segundo Afonso Berardinelli, estaria a origem das primeiras formas de ensaísmo. A coleção de retratos estaria, também, na origem da historiografia literária - e é desse modo que Speranza emprega esses 
perfis individuais para estabelecer um grande painel, cujo verdadeiro fundo é o momento único no qual essas vozes se dão, ou seja, durante a primeira década das (assim chamadas) democracias latino-americanas pós-ditatoriais. Nas vozes de autores e soldados residem a melancolia, o pessimismo e os fantasmas do passado recente, em forte contraste com o otimismo do discurso oficial e o entusiasmo propagado pelas políticas econômicas neoliberais, fazendo desses dois livros documentos importantes para se compreender essa passagem histórica.

A esses se soma ainda o catálogo, por ela produzido, de um dos mais expressivos artistas plásticos de seu país, Guillermo Kuitca, além de outra série de entrevistas, agrupadas sob o título Razones intensas (1999), dessa vez com autores e críticos anglófonos, incluindo Susan Sontag, Edward Said, Harold Bloom, George Steiner, Andreas Huyssen e Frederic Jameson.

A partir de então, em princípios do século XXI, Speranza adentra a área teórica e passa do retrato e do álbum-catálogo para telas mais amplas, traçando verdadeiras paisagens tanto temporais quanto geográficas. Assim inaugura essa nova fase de sua carreira, dedicando um estudo àquele que é provavelmente o mais imagético escritor argentino, cujo resultado pode ser lido em Manuel Puig: despues del fin de la literatura. Analisando suas relações com a arte pop e minimalista, com o cinema hollywoodiano e com as neovanguardas, Speranza coloca esse autor singular - tantas vezes considerado exótico, causando sempre sentimentos ambivalentes em críticos e dificuldades para historiadores - como capaz de produzir novas redes de organização do corpus latino-americano dentro de um panorama mundial.

Depois de se aventurar em território ficcional com o romance Ofícios ingleses (2003), a autora retoma o ensaio no trabalho pelo qual ficaria mais conhecida: Fuera del campo: literatura y arte argentinos después de Duchamp (2006). Pode-se descrevê-lo como uma historiografia especulativa da literatura argentina com base em um não evento, um encontro extraordinário e cheio de possibilidades que, a despeito da oportunidade, permaneceu sem acontecer. Trata-se da estadia de Marcel Duchamp em Buenos Aires entre 1918 e 1919, durante a qual realizou apenas uma obra de que se tenha notícia (e que depois seria reencenada narrativamente por Roberto Bolaño em 2666) e estabeleceu pouquíssimo contato com os artistas locais. A própria Speranza busca reconstituir esse episódio, numa pesquisa que tem algo de indignação ou espanto justamente por nada encontrar, apesar de todas as afinidades que havia 
entre as pesquisas estéticas que eram realizadas pelas vanguardas argentinas naquele momento e o artista francês.

A autora passa então a agir dentro de um "como se fosse" que parece mais plausível do que a total inexistência de quaisquer rastros históricos concretos que pudessem ser encontrados. Lê Borges, Puig, Piglia e outros fazendo de Duchamp o precursor deles - e vice-versa. Acaba com isso acionando um questionamento maior sobre a adequação dos conceitos de "campo" e de "autonomia", que balizaram as noções de modernidade e vanguarda para toda uma gama de teóricos das artes no século XX. Nos territórios latino-americanos, esses conceitos sempre foram colocados como uma espécie de horizonte inalcançável, dividendos que a arte do continente nunca conseguiu saldar. Speranza mostra, no entanto, que é pelos modos como os autores latino-americanos viraram a autonomia pelo avesso que a produção desse continente passou a ser considerada única, singular.

Por fim, em 2012, Speranza lança Atlas portátil de América Latina: arte y ficciones errantes, organizado como uma cartografia móvel, feita em discussão com grandes teóricos da imagem, tais como Aby Warburg, Walter Benjamin e Jacques Ranciére, revendo seus princípios a partir desse espaço geográfico ao qual eles parecem dar pouca atenção. $\mathrm{O}$ volume se inicia, inclusive, com uma reflexão suscitada por uma visita à exposição Atlas, como levar o mundo nas costas?, organizada por DidiHuberman em 2011, na qual Speranza encontra como único representante do mundo hispânico-americano uma cópia de Atlas, de Jorge Luis Borges. Entretanto, aqui não se trata de revanchismo, mas de uma verdadeira oportunidade crítica: estabelecer novas premissas, desenvolver potências latentes, trazer o princípio do atlas para novos mundos. Para tanto, o livro é composto de maneira peculiar, revezando entre ensaios, constelações de citações, registros fotográficos, entre outros fragmentos, que abarcam artistas como Mario Bellatin, Roberto Bolaño, Carlos Busquet, Francis Alÿs, Gabriel Orozco, Yuri Herrera, Sergio Chejfec, entre outros, muitas vezes lidos em conjuntos, formando redes de tensão. O livro foi finalista do Premio Anagrama de Ensayo.

A entrevista que se segue foi realizada entre novembro de 2013 e janeiro de 2014, logo depois que tive a oportunidade de acompanhar o curso regular de Speranza na Facultad de Filosofía y Letras da Universidad de Buenos Aires, onde ela é docente. Devido a motivos alheios, este diálogo até agora permaneceu inédito, transformando-se, anacronicamente, 
num registro sobre as principais linhas de força dessa pesquisadora, uma retrospectiva que prepara terreno para sua mais nova obra, Cronografías: artes y ficciones de un tiempo sin tiempo (2017).

1. Creio que poderíamos começar por essa noção de "atlas" que norteia o seu livro. Que tipos de estratégias envolvem esse mecanismo, não só como matéria de composição para os diversos artistas com os quais você dialoga, mas também como modo de organização de um pensamento crítico-teórico?

O "princípio atlas" como forma de conhecimento através da montagem tem uma larga tradição no século XX, central na obra de Aby Warburg e seu Atlas Mnemosyne, mas também no pensamento constelar de Benjamin e Bataille, e nas vanguardas históricas. A montagem dispõe as diferenças, decompõe e recompõe o mundo para que possamos voltar a vê-lo, com distância e estranhamento. A herança formal desses dispositivos não só atravessa a paisagem da arte contemporânea - muita arte de hoje compõe seu próprio atlas - mas também, como modo de organização do pensamento crítico-teórico, convida a pensar a história da arte já não como uma sucessão de mortes e ressurreições, senão em toda a sua diversidade, em seus atritos e suas sobrevivências fantasmais. Daí que o atlas me pareça uma forma muito apropriada para voltar a pensar a América Latina através da arte de hoje, para além dos coletivos identitários clássicos ou as visões do Outro que aplainam as tensões em uma amável convivência multicultural. $\mathrm{O}$ atlas, além disso, permitiu-me reunir a reflexão crítica sobre artes visuais e literatura segundo minha própria experiência de espectadora e leitora que trama relações e detecta "sobrevivências" em andamento, e também convidar o leitor a infiltrarse pelos intervalos e ampliar as séries. Nesse sentido, o atlas não quer ordenar nem sistematizar, mas justamente o contrário. $O$ heterogêneo não traz respostas firmes nem consoladoras, mas sacode nossas certezas, inquieta e põe o pensamento em movimento.

2. Tal como aparece na Introdução, Atlas portátil de América Latina surge como resposta a uma situação um tanto paradoxal: no momento em que a produção latino-americana consegue um lugar legitimado dentro do circuito internacional das bienais, dos museus e das mostras, esse lugar se torna um problema, está 
envolto por economias mercadológicas e discursivas globalizadas que neutralizam os conflitos estéticos e políticos que são colocados através das obras de arte. Essa seria uma espécie de sina das artes latino-americanas e de outras produções vindas de territórios periféricos? Existe um lugar possível para elas dentro de uma lógica de artes mundializada?

Esse paradoxo, efetivamente, é um dos efeitos da globalização cultural e, em termos mais amplos, do capitalismo global. Basta pensar no "novo espírito do capitalismo" - descrito por Luc Boltanski e Eve Chiapello - que absorveu e tomou para si boa parte das palavras de ordem, usos e valores da crítica artística da tradição anticapitalista. Enveredada no multiculturalismo e no politicamente correto, a cultura dos centros deu um lugar para as culturas periféricas. Mas, queremos esse lugar? Queremos um lugar nos novos parques temáticos da cultura globalizada? Queremos produzir novos fetiches colecionáveis da "diversidade”? E, na direção contrária: queremos que os artistas da América Latina trabalhem, consciente ou inconscientemente, para ocupar esse lugar? Acredito mais que temos que criar nosso lugar, sem nos submetermos mais à esfera global hierárquica que aloca as culturas locais anulando as tensões, para podermos complexificar a rede com relações flexíveis que preservem a tensão e aumentem a variedade das ligações. A arte latino-americana não deveria ter que mostrar passaportes para encontrar seu lugar, nem tampouco perder sua singularidade para poder figurar e reconfigurar o mundo a sua maneira. E a ideia de uma arte errante, precisamente, despreza a organização hierárquica entre centros e periferias. Não a dissolve, com certeza, mas, como disse o cubano Iván de la Nuez, fratura diques, arromba comportas. Agita as marés. Esse pode ser um bom lema para a era global: abrir-se para todo tipo de correntes que alteram a direção dos intercâmbios e o efeito dos entrecruzamentos das culturas locais.

3. No seu livro, a ideia de errância tem um papel central, ao mesmo tempo em que muitas das obras ali discutidas - tais como a de Francis Alÿs ou a de Faivovich \& Goldberg - enfatizam essas barreiras aparentemente mínimas, mas intransponíveis, que aparecem em contraste com grandes planos de mobilidade, sejam eles globais ou históricos. O gesto de "The loop” de Alÿs, ao qual você dedica um capítulo, consistiu na recusa do artista belga-mexicano, convidado para participar da mostra internacional inSITE, em fazer a viagem 
de Tijuana a San Diego simplesmente atravessando a fronteira entre México e Estados Unidos; ele fez, ao invés disso, uma grande e tortuosa volta pelo sul da América Latina, seguida por uma longa curva pela Oceania e Leste Asiático. Ou, para citar um exemplo literário, há esse esgotamento ou uso contraditório do flâneur, impossibilitado de transitar na cidade, tal como aparece no Sergio Chejfec de Mis dos mundos. Por que artes e ficções errantes estão tão envolvidas, contraditoriamente, com certo limite intransponível ou paralisia?

O passeio urbano e a viagem têm uma larga tradição na cultura e na arte do século XX, mas são exatamente certos limites intransponíveis do mundo no século XXI, como a paisagem caótica, a superpopulação ou o "cinturão de lixo", que hoje caracterizam as grandes cidades latino-americanas - efeitos derivados da modernização plena nunca alcançada -, que inspiram Alÿs e outros artistas e escritores contemporâneos a reescreverem essa tradição criando relatos espaciais que formam pontes, desenham limites mais porosos ou abrem possibilidades de territórios de passagem. Às vezes, com certo humor irônico, a obra mesma corporifica essa paralisia, como no caso de La DS, o Citröen cortado e reduzido de Gabriel Orozco, exacerbado na sua aerodinâmica, porém tornado inútil. Um monumento contemporâneo, entre outras coisas, a um dos pesadelos mais recorrentes da vida urbana: o movimento estático que todos experimentamos nos congestionamentos de trânsito. E, no entanto, o movimento, ou a tensão que você apontou entre movimento e estase, está implícito em muitas de suas obras com outros signos, como, por exemplo, nessa bola de massa de modelar que deixou rodando pelas cidades, aberta aos detritos e aos resíduos, uma boa metáfora de um percurso que não impõe senão que recebe e cede, que não quer ocultar os restos, os detritos urbanos, mas que os hospeda, compõemnos à sua maneira. Falo no livro que Piedra que cede é uma espécie de contraface rudimentar de $L a D S$, uma bola oleosa, suja, porosa, que faz da instabilidade escorregadia sua fortaleza e, portanto, uma versão auspiciosa do movimento na vida das cidades, ou, melhor dito, o movimento tal como é possível hoje em nossas grandes cidades.

4. Essa situação de fracasso da integração no momento em que ela ocorre parece volta e meia se repetir - penso, por exemplo, na ocasião do "boom" literário latino-americano. Há diferença entre o que ocorre hoje e o fenômeno dos anos 1960-1970? Não é sintomático 
que atualmente haja uma referência em torno de um novo "boom", principalmente em torno da recepção norte-americana dos romances de Roberto Bolaño?

O problema que está por trás de sua pergunta é a identidade latinoamericana. Existe uma arte latino-americana? Existe uma cultura latino-americana? E ainda antes: o que é América Latina? Creio que não há outra região ou continente que volte com tanta insistência a essas perguntas, a ponto de o cubano Gerardo Mosquera falar, com razão, de uma "neurose identitária" latino-americana. A identidade coletiva pode ser estrategicamente produtiva em certas conjunturas econômicas ou geopolíticas, mas os essencialismos nunca nos levaram muito longe no pensamento da arte e cultura, estimulando, ao invés disso, os estereótipos redutores. Aí estão os efeitos do boom para provar isso, a despeito do mérito individual de seus escritores.

O fenômeno Bolaño é complexo, sobretudo nos Estados Unidos. Não creio, como pensam alguns críticos, que Bolaño seja o último gemido do boom latino-americano. Há algo da grande tradição literária estadunidense que os americanos encontram revivido no espírito "On the Road” de Bolaño. Ainda há muitos outros fatores: a morte prematura, a vida literária, o cosmopolitismo surrealista. Porém, insito: resisto em pensar a literatura de Bolaño a partir da recepção estadunidense, como resisto em pensar a literatura de Cortázar somente a partir dos vai e vens da recepção argentina. Creio mais com Borges que nossa tradição é todo o universo e que temos que pensar em nossos artistas e escritores nos torvelinhos dessas correntes e contracorrentes culturais.

\section{Parece-me que sua proposta é reler Cortázar e Bolaño buscando} recuperar a importância de uma tradição surrealista do continente, uma tradição que tem sido solapada ao longo das décadas. Afinal, por que o surrealismo latino-americano tornou-se "subterrâneo" e como ele se mantém vivo hoje? E por que a obra de Cortázar continua a ser um ponto de dissenso tão grande para a crítica argentina e latino-americana?

A virtual ou estratégica certidão de óbito do surrealismo na América Latina é um caso em si mesmo, extenso e complexo de explicar. Digamos, para resumir, que para nos livrarmos do estereótipo do realismo mágico, a maravilha irracional com que passou a identificar a identidade latino-americana, 
nos livramos, ao mesmo tempo e por via das dúvidas, de qualquer sinal de irracionalismo e, portanto, apagamos o surrealismo como caminho estético duradouro dos relatos históricos. O surrealismo converteu-se em uma relíquia ou banalizou-se em versões ingênuas ou esotéricas. Mas, ainda assim, o surrealismo retorna (cada época possui seus surrealistas, dizia Man Ray): reviveu transfigurado mais além das escolas oficiais nas leituras de Julio Cortázar e em sua obra narrativa. E pode ser que se encontre aí, finalmente, a distância insuperável que o separa de Borges, apesar de suas muitas coincidências. Borges via o surrealismo com desdém, alheio ao seu nominalismo filosófico e ao rigor que demandava da arte narrativa, e numa de suas típicas dicotomias vernáculas, a crítica argentina pleiteou o enfrentamento nos anos 1980 com a supremacia de Borges e o progressivo descrédito de Cortázar. Mas se prestamos atenção no início de percurso de alguns dos escritores e artistas mais renovadores das últimas décadas, descobrimos que há um surrealismo clandestino, como dizia Bolaño, que seguiu vivo e foi germe de uma arte errante, desarraigada, que quer voltar a conjugar a paixão do real e a graça geradora do acaso. "Deixem tudo para trás. Se lancem pelas estradas", diz o manifesto infrarrealista de Bolaño, recuperando Breton. É o começo de uma obra hipercinética, tentacular, que quer reunir tudo em um turbilhão, voltar a entrelaçar arte e vida.

\section{Voltando à questão do lugar da América Latina: se a identidade} é uma estratégia por vezes duvidosa, e constantemente posta em questão pelos artistas que aparecem em Atlas portátil, há por outro lado uma insistência, com dimensões utópicas, em compor outros modelos de relação comunitária, tais como aparece nas obras do artista plástico Tomás Saraceno, que propõe outras formas de relação entre arte, natureza e sociedade, entre estética, formas de vida e técnica. Proposta essa que está no centro das atenções de certa renovação do pensamento antropológico, como aquele proposto por Bruno Latour, ou ainda por Eduardo Viveiros de Castro. O que muda hoje com relação àquela velha ideia de que a arte é capaz de produzir formas de convivência? E como ela responde a essa "neurose identitária" que assombra a história da América Latina?

Efetivamente, a ideia de uma convivência em escala planetária fez com que muitos artistas voltassem sua atenção para a ciência, a tecnologia, a ecologia, a dimensão biopolítica e a consideração mais matizada da oposição convencional entre esferas e redes com que se 
descreve a globalização, um termo vazio que não acerta em definir a peculiar relação entre localidade e globalidade. Para muitos artistas, a arte se transforma em um laboratório ou um modelo de possíveis configurações flexíveis, topológicas, do tempo e espaço, que convidam a olhar o presente e o futuro de outro modo. Penso por exemplo na obra do jovem artista argentino Adrián Villar Rojas, grandes instalações efêmeras, feitas de argila e cimento, que compõem uma paisagem de restos da cultura humana tal como poderia vê-la um extraterrestre num futuro longínquo, fazendo com que em nosso presente ela já seja uma ruína. Em suas últimas obras, como a da Serpentine Sackler Gallery, que foi inaugurada com uma instalação sua e que acabo de ver em Londres, Villar Rojas redemoinha os tempos, apaga os limites entre cultura e natureza, convida a "reiniciar" a narrativa que fazemos do planeta (Today We Reboot the Planet, chama-se a obra), pensando a intervenção do homem de outro modo, preocupações que estão em sintonia com as de Bruno Latour e outros pensadores contemporâneos. É certo que já não cremos ingenuamente no poder emancipador da arte, nem naquela utopia de uma vanguarda estética aliada com a vanguarda política, ideias que conduziram o século XX. Mas segue viva a potência da imaginação artística, que pode criar metáforas do presente e antecipar o futuro, que convida ao dissenso diante dos consensos generalizados e é capaz de imaginar configurações que outras linguagens ainda não podem formular. "Pessimismo da inteligência, otimismo da vontade", dizia Gramsci. Eu acrescentaria: "Imaginação da arte”.

7. Ainda nesse ponto sobre o lugar das artes, creio que essa também é a passagem que se dá entre seu novo livro e o anterior, Fuera del campo. Se neste a ênfase estava posta no conflito que existe entre certas obras argentinas e latino-americanas com relação aos limites do campo simbólico-institucional aos quais elas estão associadas; em Atlas portátil de América Latina, a questão parece envolver a necessidade de reconstrução de um território ou de marcos de localização de outra ordem, geográficos, mas também estéticos. A natureza dos termos - "campo" e "atlas" - parece anunciar um problema topográfico, por assim dizer. Afinal, como se deu essa passagem e qual a relação que há entre esses termos?

Você tem muita razão ao apontar isso: a expansão dos campos, o princípio atlas e também as "formas errantes" remetem ao espaço, à 
espacialização do tempo e, inclusive, à topologia, ao movimento, ao dinamismo das formas. No caso de Fuera de campo, o foco estava na expansão dos campos artístico, na perda da especificidade dos meios; no Atlas, trata-se mais de se dirigir às formas que figuram deslocamentos espaciais, ou inclusive espaços aterritoriais que perfuram os estados e os articulam de outro modo. Formas ou artefatos "radicantes", como os chama Nicolas Bourriaud, que se alimentam de enraizamentos sucessivos e simultâneos sem hibridar culturas, senão mantendo em tensão a disparidade de suas tradições e suas polaridades. Em ambos os casos, o foco está posto no "entre dois", no intervalo entre um meio e outro, uma cultura e outra, uma tradição e outra, uma língua e outra.

8. E há, é claro, esse outro elo entre seus dois livros, entre as questões que eles buscam enfrentar: a obra de Marcel Duchamp. Por que pensar as manifestações artísticas e literárias latino-americanas a partir dos dispositivos duchampianos tornou-se algo tão produtivo? Inclusive a figura dele aparece de forma destacada na produção literária recente, como no caso de Bolaño e de Mario Bellatin. A que se deve isso?

Um historiador da arte que admiro muito, Benjamin Buchloh, descreveu o lugar de Duchamp na arte do século XX com uma comparação bastante ilustrativa. Disse uma vez que não teria problemas em admitir que sofria de uma "fixação por Duchamp", da mesma maneira que um físico sofre sem dúvida de uma "fixação por Einstein". O comentário ilustra bem o lugar de Duchamp na história da arte contemporânea, um legado cuja dimensão somente agora, com certa perspectiva, começa a se fazer evidente também na arte argentina e latino-americana. Como nenhum outro artista do século, Duchamp estende seu influxo a toda arte futura e alcança inclusive artistas que nunca conheceram sua obra. Segue permanecendo "no ar", para usar uma expressão de Bruce Nauman, e "volta aos outros criadores", como uma vez sentenciou John Cage. A pergunta delicada que formulou em 1913 - "É possível fazer obras de arte que não sejam obras de arte?” - permaneceu efetivamente vibrando no ar do século como um antídoto contra a cruzada purificadora do modernismo, como um convite a aproximar a arte às coisas e um chamado para liberá-la de qualquer essencialismo redutor. A preeminência da ideia sobre a materialidade do meio tornou irrelevantes as distinções entre linguagens e suportes, antecipando uma virada conceptual irreversível que alcança todas as artes 
e também a literatura. Em sua esteira, a liberdade do artista se tornou ilimitada, e a arte pode ser hoje aquilo que o artista decide.

Em Fuera de campo tentei, deliberadamente, voltar a ler a literatura e a arte argentinas a partir de uma espécie de "efeito Duchamp". Num primeiro momento, a operação parece arbitrária, uma vez que eu mesma me encarrego de demonstrar que pouco sobrou dessa estadia de Duchamp em Buenos Aires em 1918. Porém, é mais o vazio que ela deixou atrás de si que a torna tão estimulante para a especulação crítica. O vazio, como em grande parte de sua obra, se oferece como uma "máquina do olhar". O que se vê através da lente duchampiana que ainda não havíamos podido ver? Em alguns casos, tratava-se de restituir diálogos reais com Duchamp, como em Cortázar ou Aira. Em outros, como em Macedonio, Borges ou Puig, sem essa causalidade de efeitos, é possível pensar a interação entre pensamento, visão e palavra, interação esta que também aparece na literatura e na arte argentinas. Borges e Duchamp, por exemplo, nunca se conheceram e nunca mencionaram um ao outro, mas a coincidência de algumas preocupações estéticas, talvez mediadas por Paul Valéry, é inquestionável.

No Atlas, as relações são mais explícitas. Muitos dos artistas que me deram mais o que pensar são artistas marcados pela herança da arte conceitual, e o diálogo com Duchamp é evidente. Talvez o mais surpreendente seja a marca duchampiana nos escritores, mas ela também é explícita nos casos em que você mencionou. O que acontece é que a especialização e os compartimentos dos campos frequentemente empobrece a leitura crítica, incapaz de reconstituir as relações que os escritores mesmos tramaram. O Atlas quer reunir artes visuais e literatura, entre outras coisas, porque muitos artistas e escritores contemporâneos criam hoje a partir desse intercambio entre meios e linguagens.

9. Há alguns anos, Josefina Ludmer escreveu um texto em que apontava o caráter "pós-autônomo" de certas obras da literatura argentina contemporânea e do campo artístico em geral, um ensaiomanifesto que gerou inúmeras repercussões, tanto positivas como negativas. E o seu livro Fuera de campo foi invocado várias vezes como referência para pensar essa proposta de conceituação de um novo estágio do campo estético. Entretanto, em Atlas portátil, você aponta alguns limites dessa "literatura pós-autônoma". Como você vê esse conceito? Haveria de fato uma situação generalizada que poderíamos classificar de "pós-autonomia”? 
O termo pós-autonomia apareceu em princípios do novo século nas esferas das artes visuais pela primeira vez, se não me engano, num texto de um crítico russo do círculo de Ilya Kabakov, Víctor Tuptsyn, em referência à arte de instalação e, mais precisamente, à obra do britânico Damien Hirts e seu virtual apagamento das fronteiras entre arte autônoma e indústria cultural. Entre nós, Josefina Ludmer o trouxe à literatura argentina há alguns anos para nomear novas práticas literárias que a seu ver assinalavam o fim do ciclo da autonomia literária, dos limites claros da especificidade e da autorreferencialidade: escrituras que são e não são literaturas, são realidade e são ficção, e estão para além dos critérios tradicionais do juízo e do valor. O argumento sintoniza oportunamente transformações de certa literatura de hoje, mas é difícil entender por que Ludmer segue delimitando seu olhar à literatura, se a dissolução das fronteiras é tamanha, e por que não se serve, por exemplo, de literaturas que atravessaram de forma muito evidente as fronteiras dos campos artísticos e dialogam com as artes visuais ou com a performance, ou por que não trata simultaneamente da arte contemporânea. Custa também entender com quais critérios escolhe as obras que escolhe - e o que vê em cada caso -, se essas literaturas estão para além de qualquer critério conhecido de seleção, juízo ou valor. A denominação mesma - pós-autonomia não parece muito feliz e promete tantos equívocos quanto aqueles que suscitaram a pós-modernidade. Em princípio porque teríamos que definir de que autonomia estamos falando, se da autonomia adorniana em relação à indústria cultural, se da autonomia enquanto especificidade dos meios, das disciplinas, das esferas, dos campos. Minhas leituras em Fuera de campo e também em Atlas vão nessa direção. Em segundo lugar, e, sobretudo, porque se diria que já não cabe falar de "neos" e "pós" na arte contemporânea. A lógica dialética que ordenou as rupturas de vanguarda e dos grandes movimentos do século XX não parece capaz de explicar mais as transformações e o pluralismo estético da arte de hoje: nem a estratégia opositora do "pós", nem a recursividade do "neo" dão conta de uma coexistência de suportes, materiais, linguagens e práticas que convivem sem o afã de impor paradigmas.

Diluídas as fronteiras entre o alto e o baixo, a dialética do "neo" e do "pós" e as definições essencialistas dos meios, a pós-modernidade fez da sua bandeira a promessa de uma liberdade sem precedentes: todas as imagens, objetos, formas, textos, meios, práticas e linguagens gozam em principio de igualdade de direitos estéticos sem diferenças 
hierárquicas. Mas é possível que a igualdade do diverso siga sendo tão utópica e ideológica como a igualdade na identidade que promoveram os cânones modernos. A arte ainda aspira a criar algo que antes não existia e a diversidade dos caminhos possíveis não elimina, em termos práticos, a discussão sobre a inovação e o valor. Boris Groys ataca o centro nevrálgico da discussão em Sobre o novo, uma consideração da economia do intercâmbio renovador na cultura contemporânea. As instalações, os museus, os arquivos globalizados da cultura seguem auscultando o presente em busca do novo. E perguntar pelo novo é perguntar pelo valor, na medida em que o novo não é simplesmente o "outro", senão o outro suficientemente valioso para ser detectado, considerado criticamente, extraído da corrente indiferenciada do diverso e conservado, como propõe Groys. Sequer os intentos mais radicais de distanciar-se das instituições de arte e abandonar a discussão do valor podem escapar de determinados critérios de seleção. Não há autor que tenha entrado no corpus exemplificador da literatura da "realidadeficção" de Ludmer sem uma seleção anterior, cujos verdadeiros critérios não são explicitados. Se já não conta o valor, por que não fazê-lo dar lugar entre as obras já reconhecidas a outras, imitativas, ingênuas, triviais ou francamente ruins, com igual vocação para a "realidadeficção"?

Creio mais que existe ainda uma intencionalidade estética que distingue a arte da não arte, e que o pluralismo bem informado não dispensa espectadores, leitores e críticos do juízo estético. Embora seja verdade que a arte de hoje exige um treinamento para se apreciar estratégias e destrezas alternativas, para analisar formas da arte em que se prioriza a ideia sobre a matéria por sua capacidade de promover leituras múltiplas e significativas, para detectar regras que se impõem ao artista de arte sem gênero e sem meio específico e observar como as cumpre e o que obtém em troca, para apreciar a qualidade das relações que produz uma arte participativa e relacional. Ainda nas obras que descreem do projeto e da técnica, brilha certo grau de eficácia, talento e graça. 